\title{
Comparison of Cocaine Detections in Corona Discharge Ionization-Ion Mobility Spectrometry and in Atmospheric Pressure Chemical Ionization-Mass Spectrometry
}

\author{
Sung-Seen Choi, ${ }^{*}$ Yun-Ki Kim, Ok-Bae Kim, Seung Geon An, ${ }^{\dagger}$ Myung-Won Shin, ${ }^{\dagger}$ Seug-Jin Maeng, ${ }^{\dagger}$ and Gyu Seop Choi ${ }^{\dagger}$ \\ Department of Chemistry, Sejong University, Seoul 143-747, Korea. *E-mail: sschoi@sejong.ac.kr \\ ${ }^{\dagger}$ Wooju Communication \& Technology Co., Rm610, Kolon Science Valley 2nd. 811, Guro-dong, Guro-gu, Seoul 150-732, Korea \\ Received April 27, 2010, Accepted June 19, 2010
}

Key Words: IMS, APCI-MS, Cocaine, Detection limit

Ion mobility spectrometry (IMS) was a technique originally applied for the detection of trace compounds. ${ }^{1-3}$ IMS has been widely used to detect chemical warfare agents, ${ }^{4-6}$ explosives, ${ }^{7-10}$ and illegal drugs ${ }^{10-13}$ since it combines both high sensitivity (detection limits down to the $\mathrm{ng} / \mathrm{L}$ range to $\mathrm{pg} / \mathrm{L}$ range, $\mathrm{ppb}$ range and ppt range) and relatively low technical expenditure with high-speed data acquisition. The time required to acquire a single spectrum is in the range of several tens ms. The working principle is based on the drift of ions at ambient pressure under the influence of an external electric field. ${ }^{14-20}$ IMS works in a similar way to a time-of-flight mass spectrometer (TOFMS). The major difference is that TOFMS requires a vacuum but IMS does not. The mean free path of the ions in IMS is very smaller than in TOFMS. A typical IMS is comprised of an ionization source associated with an ion reaction chamber, an ion drift tube, an ion/molecule injection shutter placed between the ion reaction chamber and the ion drift tube, and an ion collector (detector, Faraday plate). An ion swarm drifting under the electric field experiences a separation process based on ions with different masses or structures having different drift velocities. Collecting these ions on a Faraday plate delivers a time-dependent signal corresponding to the mobility of the arriving ions. This ion mobility spectrum contains information on the nature of the different trace compounds present in the sample gas.

Mass spectrometry is an important tool for the structural analysis of unknown chemicals. Soft ionization techniques such as matrix-assisted laser desorption and ionization (MALDI) and atmospheric pressure ionization (API) have been used for determination of molecular weight of an analyte. ${ }^{21-34}$ Electrospray ionization (ESI) and atmospheric pressure chemical ionization (APCI) are the most currently used as API sources. In APCI, a corona discharge makes solvent reactant ions that are used to ionize the analyte by chemical ionization. ${ }^{31-34}$ Solvent and analyte are vaporized by pneumatic nebulization. APCI relies upon gas-phase ion-molecule reactions to place a charge on neutral analytes, so it is especially important to understand these reactions. The solvent-derived ions serve as reagents for proton transfer ionization.

Cocaine is a powerfully addictive drug because of its instantaneous and overwhelming effects on the central nervous system. It is generally analyzed by gas chromatography/mass spectrometry (GC/MS), liquid chromatography/mass spectrometry (LC/MS), GC, or LC. Recently, it has been analyzed using IMS. ${ }^{11,35-37}$ Lu and coworkers ${ }^{35}$ analyzed cocaine and its metabolites, benzoylecgonine and cocaethylene in urine using solid phase extraction (SPE) coupled with IMS, and reported that the detection limits of benzoylecgonine and cocaethylene are $10 \mathrm{ng} / \mathrm{mL}(10 \mathrm{ppb})$ and $4 \mathrm{ng} / \mathrm{mL}$ (40 ppb), respectively. Dussy and coworkers ${ }^{36}$ examined the validation of a qualitative IMS procedure for the detection of trace amounts of cocaine on incriminated material using a vacuum cleaner for sampling and reported that the detection limit of cocaine was $0.2 \mathrm{ng}$.

We constructed IMS equipped with corona discharge ionization source and its performance was tested using cocaine. Ionization sources used in IMS are ${ }^{63} \mathrm{Ni}$ ionization ( $\beta$-ionization), photoionization (PI), and corona discharge (CD) ionization. The corona discharge ionization source is relatively new ionization method in IMS. ${ }^{38}$ IMS equipped with ${ }^{63} \mathrm{Ni}$ ionization source can be used for manifold applications including chemical warfare agents, drugs, explosives, and environmental and industrial analyses. Unfortunately, it contains radioactive nickel. Furthermore, the ${ }^{63} \mathrm{Ni}$ ionization source has low electron energy and its applications are restricted to the determination of aromatic and unsaturated compounds. However, as known from the literature, corona discharge ionization can be used for ionization of a broad range of different classes of chemical compounds. $^{39-43}$

In this study, we determined the detection limit and reproducibility of the new IMS equipped with corona discharge ionization source using cocaine. The sample was injected with liquid solution to compare the results of APCI-MS. An illustration of the basic ionization process of cocaine in the IMS is presented in Figure 1. The sample solution of $1 \mu \mathrm{L}$ was injected

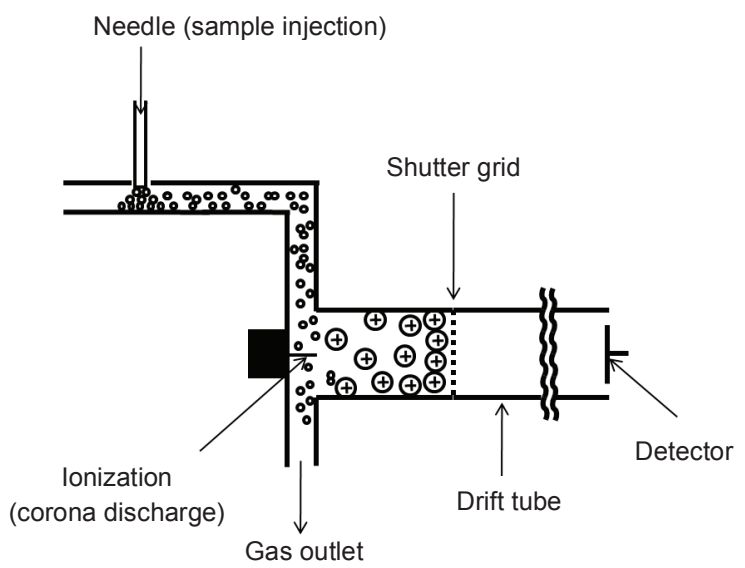

Figure 1. Schematic diagram of ionization process in ion mobility spectrometer. 


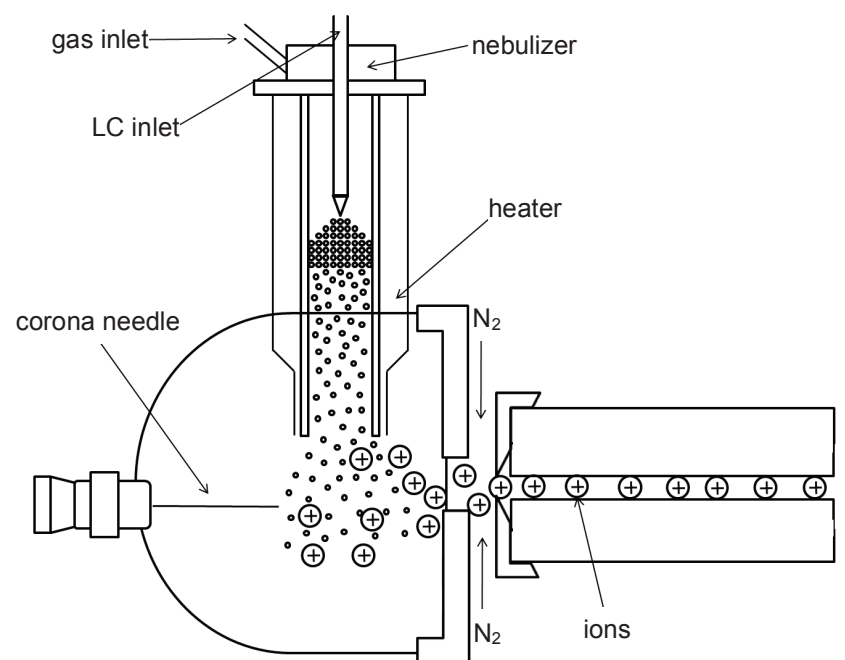

Figure 2. Schematic diagram of ionization process in atmospheric pressure chemical ionization-mass spectrometer.

into the hole. The sample evaporated and flowed to the ionization chamber. Vapors of the solvent (acetonitrile) and cocaine, air (nitrogen and oxygen), and water vapor exist in the ionization chamber. These gases are ionized by corona discharge and the product ions are formed by the ion-molecule reactions. The product ions in the front of the shutter grid drift to the detector. For APCI-MS (Figure 2), the liquid sample evaporates through the nebulizing region and the vapors are ionized by corona discharge. The product ions are extracted to the capillary linked to the mass spectrometer.

Cocaine was analyzed with APCI-MS. Both positive and negative modes were performed. In the positive mode, the APCI mass spectrum of cocaine displayed only the protonated molecule, $[\mathrm{M}+\mathrm{H}]^{+}$. But, in the negative mode, any product ion related cocaine was not observed. In order to determine the detection limit of cocaine in APCI-MS, the ion intensity was observed as the concentration decreased. The fragmentor voltage was determined to $150 \mathrm{~V}$ by comparing the ionization efficiencies according to the fragmentor voltages. The detection limit of cocaine in APCI-MS was $10 \mathrm{ppb}$ in acetonitrile (the injection volume $10 \mu \mathrm{L}$ ). That is, the detection limit was about $0.1 \mathrm{ng}$. The calibration curve of cocaine in APCI-MS of the range of $10-200 \mathrm{ppb}$ was obtained as shown in Figure 3. The curve fitting equation of the calibration curve was $\mathrm{y}=506 \mathrm{x}$ $922(r=0.997)$. The experimental results say that analysis of cocaine using APCI-MS had good detection limit and was good for quantitation.

The cocaine solution in acetonitrile of $1 \mu \mathrm{L}$ was introduced into the IMS and analyzed to examine the detection limit and reproducibility. The analysis was performed five times at each concentration to check the reproducibility. Both positive and negative modes were performed. The product ion of cocaine was only generated in the positive mode (Figure 4). Besides the peaks of acetonitrile and reactive gases (air and water molecules), only one new peak was observed in the IMS spectrum. Considering the APCI mass spectrum of cocaine, the new peak must be the protonated molecule of cocaine. The drift

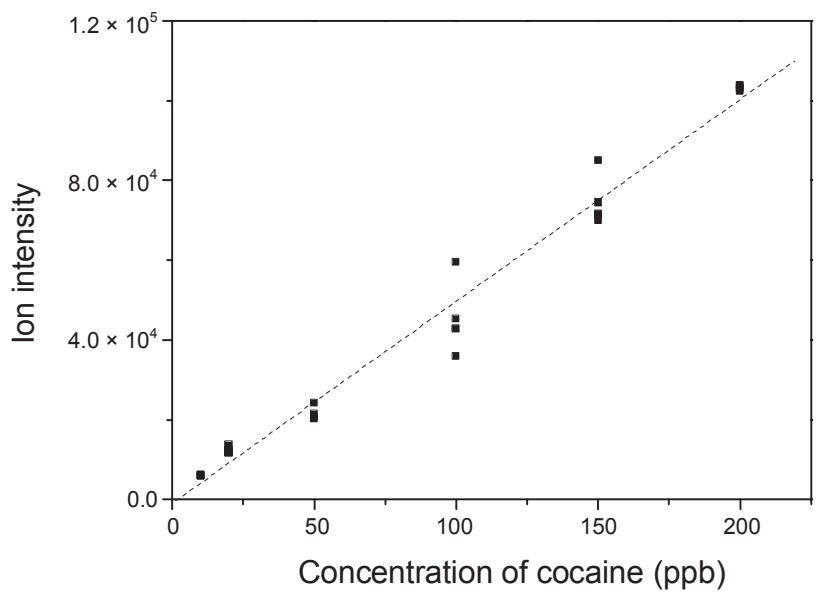

Figure 3. Calibration curve of $[\text { Cocaine }+\mathrm{H}]^{+}$detected in APCI-MS.

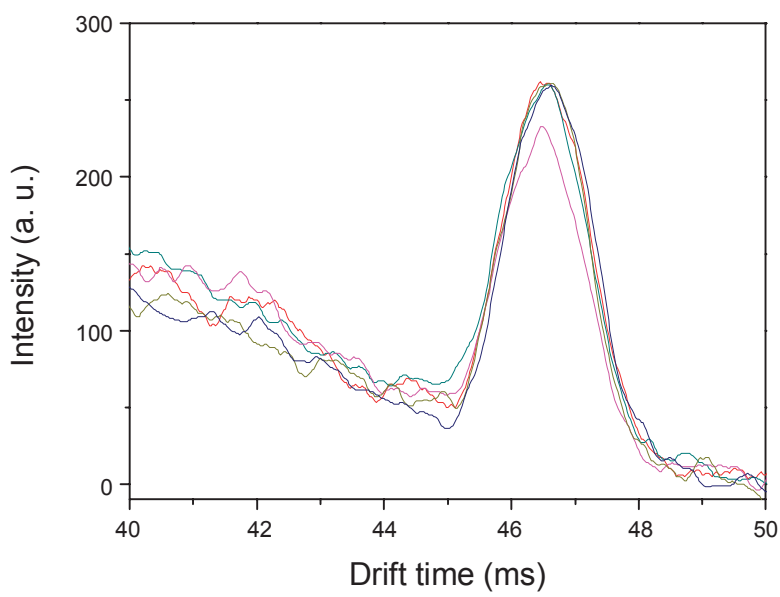

Figure 4. IMS spectra of 20 ppb cocaine.

time $\left(\mathrm{t}_{\mathrm{d}}\right)$ was $46.55 \pm 0.10 \mathrm{~ms}$. The relative standard deviation (RSD) was less than $1.0 \%$. The detection limit of cocaine in the IMS with corona discharge ionization was determined as the concentration decreased. The detection limit of cocaine in the IMS was $20 \mathrm{ppb}$. That is, the detection limit was about $0.02 \mathrm{ng}$ (the injection volume was $1 \mu \mathrm{L}$ ). This was a better detection limit than the previous result of Dussy and coworkers. ${ }^{36}$ Figure 4 shows the five IMS spectra of the $20 \mathrm{ppb}$ cocaine. RSD of the peak heights was $17 \%$. The ion mobility $\left(\mathrm{K}, \mathrm{cm}^{2} /\right.$ $\mathrm{V} \cdot \mathrm{sec}$ ) is define by equations (1) and (2).

$$
\begin{aligned}
& \mathrm{v}_{\mathrm{d}}=\mathrm{K} \cdot \mathrm{E} \\
& \mathrm{K}=\mathrm{v} / \mathrm{E}=\mathrm{L} /\left(\mathrm{E} \cdot \mathrm{t}_{\mathrm{d}}\right)
\end{aligned}
$$

where $\mathrm{V}_{\mathrm{d}}$ is the drift velocity of ion $(\mathrm{cm} / \mathrm{sec})$, E is the electric field $(\mathrm{V} / \mathrm{cm}), \mathrm{L}$ is the drift distance of ion $(\mathrm{cm})$, and $\mathrm{t}_{\mathrm{d}}$ is the transit time (drift time) of ion in the drift region (sec). The calculated $\mathrm{K}$ was $1.555 \pm 0.004 \mathrm{~cm}^{2} \cdot \mathrm{V}^{-1} \cdot \mathrm{s}^{-1}$ and its RSD was $0.5 \%$. The drift time of ion in IMS is influenced by the pressure and temperature of the drift region. The reduced ion mobility $\left(\mathrm{K}_{0}\right)$ is the pressure and temperature-corrected mobility. The reduced ion mobility is defined by equation (3). 


$$
\mathrm{K}_{0}=\mathrm{K}[(\mathrm{P} / 760) \times(273 / \mathrm{T})]
$$

where $\mathrm{T}$ is the operating temperature of the instrument $(\mathrm{K})$ and $\mathrm{P}$ is the current ambient pressure (torr). The calculated $\mathrm{K}_{0}$ was $1.124 \pm 0.002 \mathrm{~cm}^{2} \cdot \mathrm{V}^{-1} \cdot \mathrm{s}^{-1}$ and its RSD was $0.4 \%$. The previously reported $\mathrm{K}_{0}$ value was $1.16^{35}$

From the experimental results, we can conclude that the new IMS equipped with corona discharge ionization source had excellent detection limit of cocaine $(0.02 \mathrm{ng})$ and relatively good reproducibility.

\section{Experimental Section}

Cocaine of $1000 \mathrm{ppm}$ in acetonitrile was purchased from Cerilliant Co. and acetonitrile (HPLC grade) was purchased from J. T. Baker Co. The concentrated cocaine was diluted with acetonitrile to 10, 20, 50, 100, 150, and $200 \mathrm{ppb}$.

IMS equipped with corona discharge ionization source (Figure 1) was constructed by Wooju Communication \& Technology Co. The analysis conditions of IMS were as follows: temperature of the sampling region was $200{ }^{\circ} \mathrm{C}$, temperatures of the ionization chamber and drift tube were $100{ }^{\circ} \mathrm{C}$, pressure in the drift tube was 750 torr, the electric field was $154.7 \mathrm{~V} / \mathrm{cm}$, and the drift distance of ion was $11.2 \mathrm{~cm}$. The $1 \mu \mathrm{L}$ sample was injected. The IMS analyses were performed five times at each concentration.

LC/APCI-MS of HPLC 1200 instrument coupled to a single quadrupole LC-MS 6130 mass spectrometer of Agilent Technologies Inc. was used as APCI-MS. The liquid chromatograph used a binary pump and an injection valve with a $10 \mu \mathrm{L}$ sample loop. A sample of $10 \mu \mathrm{L}$ was introduced by means of a Rheodyne valve. The eluent was the same solvent and the flow rate was $1.0 \mathrm{~mL} / \mathrm{min}$. MS detection was achieved using a single quadrupole spectrometer equipped with an APCI ionization source. The following instrumental parameters were used for the $\mathrm{LC} /$ APCI-MS analysis in the positive ion mode: capillary, $-4 \mathrm{kV}$; fragmentor voltage, $150 \mathrm{~V}$; corona current, $4.0 \mu \mathrm{A}$; quadrupole temperature, $100{ }^{\circ} \mathrm{C}$; vaporizer temperature, $325^{\circ} \mathrm{C}$. The APCI$\mathrm{MS}$ analyses were also performed five times at each concentration.

Acknowledgments. This research has been supported by R\&BD Program (grant no. RBD-0901-0901-06-1) of Ministry of Knowledge Economy, Korea.

\section{References and Notes}

1. Baumbach, J. I. Anal. Bioanal. Chem. 2006, 384, 1059.

2. Mendes, M. A.; Pimpim, R. S.; Kotiaho, T.; Eberlin, M. N. Anal. Chem. 1996, 68, 3502.

3. Eiceman, G. A. Trends Anal. Chem. 2002, 21, 259.

4. Kolakowski, B. M.; D’Agostino, P. A.; Chenier, C.; Mester, Z. Anal. Chem. 2007, 79, 8257.

5. Zimmermann, S.; Barth, S.; Baether, W. K. M.; Ringer, J. Anal. Chem. 2008, 80, 6671 .
6. Rearden, P.; Harrington, P. B. Anal. Chim. Acta 2005, 545, 13.

7. Daum, K. A.; Atkinson, D. A.; Ewing, R. G. Int. J. Mass Spectrom. 2002, 214, 257.

8. Ewing, R. G.; Atkinson, D. A.; Eiceman, G. A.; Ewing, G. J. Talanta 2001, 54, 515.

9. Matz, L. M.; Tornatore, P. S.; Hill, H. H., Jr. Talanta 2001, 54, 171.

10. Kanu, A. B.; Hill, H. H., Jr. Talanta 2007, 73, 692.

11. Lai, H.; Corbin, I.; Almirall, J. R. Anal. Bioanal. Chem. 2008, 392, 105 .

12. Ochoa, M. L.; Harrington, P. B. Anal. Chem. 2004, 76, 985.

13. Buryakov, I. A.; Baldin, M. N. J. Anal. Chem. 2008, 63, 787.

14. Guo, Y.; Wang, J.; Javahery, G.; Thomson, B. A.; Michael Siu, K. W. Anal. Chem. 2005, 77, 266.

15. Shvartsburg, A. A.; Li, F.; Tang, K.; Smith, R. D. Anal. Chem. 2006, 78, 3706.

16. Kanu, A. B.; Gribb, M. M.; Hill, H. H., Jr. Anal. Chem. 2008, 80, 6610.

17. Young, D.; Eiceman, G. A.; Breach, J.; Brittain, A. H.; Thomas, C. L. P. Anal. Chim. Acta 2002, 463, 143.

18. Gillig, K. J.; Ruotolo, B. T.; Stone, E. G.; Russell, D. H. Int. J. Mass Spectrom. 2004, 239, 43.

19. Purves, R. W.; Guevremont, R.; Day, S.; W. Pipich, C.; Matyjaszczyk, M. S. Rev. Sci. Instrum. 1998, 69, 4094.

20. Lia, F.; Xiea, Z.; Schmidta, H.; Sielemannb, S.; Baumbach, J. I. Spectrochim. Acta B 2002, 57, 1563.

21. Harvey, D. J. Mass Spectrom. Rev. 1999, 18, 349.

22. Naven, T. J. P.; Harvey, D. J. Rapid Commun. Mass Spectrom. 1996, 10,829 .

23. Choi, S.-S.; Ha, S.-H. Bull. Korean Chem. Soc. 2006, 27, 1243.

24. Choi, S.-S.; Lee, H. M. Bull. Korean Chem. Soc. 2009, 30, 2806.

25. Yuan, J.; Hashii, N.; Kawasaki, N.; Itoh, S.; Kawanishi, T.; Hayakawa, T. J. Chromatogr. A 2005, 1067, 145.

26. Wan, E. C. H.; Yu, J. Z. J. Chromatogr. A 2006, 1107, 175.

27. Cheng, H. L.; Her, G. R. J. Am. Soc. Mass Spectrom. 2002, 13, 1322.

28. Zhu, X.; Sato, T. Rapid Commun. Mass Spectrom. 2007, 21, 191.

29. Choi, S.-S.; Song, M. J. Int. J. Mass Spectrom. 2009, 285, 126.

30. Choi, S.-S.; Kim, J.-C. Bull. Korean Chem. Soc. 2009, 30, 1996.

31. Choi, S.-S.; Song, M. J. Rapid Commun. Mass Spectrom. 2008, $22,2580$.

32. Choi, S.-S.; Song, M. J. Bull. Korean Chem. Soc. 2008, 29, 1847.

33. Choi, S.-S.; Kim, J.-C. Carbohydr. Res. 2010, 345, 408.

34. Choi, S.-S.; Kim, J.-C. Rapid Commun. Mass Spectrom. 2009, 23 , 3969.

35. Lu, Y.; O’Donnell, R. M.; Harrington, P. B. Foren. Sci. Int. 2009 , 189, 54.

36. Dussy, F. E.; Berchtold, C.; Briellmann, T. A.; Lang, C.; Steiger, R.; Bovens, M. Foren. Sci. Int. 2008, 177, 105.

37. Lai, H.; Guerra, P.; Joshi, M,; Almirall, J. R. J. Sep. Sci. 2008, 31, 402.

38. Tabrizchi, M.; Khayamian, T.; Taj, N. Rev. Sci. Instrum. 2000, 71, 2321.

39. Jafari, M. T.; Khayamian, T.; Shaer, V.; Zarei, N. Anal. Chim. Acta 2007, 581, 147.

40. Han, H. Y.; Huang, G.-D.; Jin, S.-P.; Zheng, P.-C.; Xu, G.-H.; Li, J.-Q.; Wang, H.-M.; Chu, Y.-N. J. Env. Sci. 2007, 19, 751.

41. Skalny, J. D.; Orszagh, J.; Matejcik, S.; Mason, N. J.; Rees, J. A.; Aranda-Gonzalvo, Y.; Whitmore, T. D. Int. J. Mass Spectrom. 2008, 277, 210.

42. Sheibani, A.; Tabrizchi, M.; Ghaziaskar, H. S. Talanta 2008, 75, 233.

43. Borsdorf, H.; Neitsch, K.; Eiceman, G. A.; Stone, J. A. Talanta 2009, 78, 1464. 